\title{
Pengaruh Sumber Kation NaOH dan KOH Terhadap Jenis Zeolit Sintetis dari Abu Dasar Batubara dengan Metode Peleburan Alkali Hidrotermal
}

\author{
Teguh Nugraha Pratama*, Afdhal Muttaqin \\ Jurusan Fisika FMIPA Universitas Andalas \\ Kampus Unand, Limau Manis, Padang, 25163 \\ *nugrahapratama.teguh@gmail.com
}

\begin{abstract}
ABSTRAK
Telah dilakukan sintesis zeolit dari abu dasar batubara dengan metode peleburan alkali hidrotermal menggunakan variasi sumber kation berupa $\mathrm{NaOH}$ dan $\mathrm{KOH}$. Perbandingan mol kation dengan massa abu dasar yang digunakan adalah 0,36 mol:12 g. Variasi perbandingan mol $\mathrm{NaOH}$ dan $\mathrm{KOH}$ yang digunakan adalah 100\%:0\% (Na100-K0), 75\%:25\% (Na75-K25), 50\%:50\% (Na50-K50), 25\%:75\% (Na25:K75) dan 0\%:100\% (Na0-K100). Peleburan alkali dilakukan pada temperatur $550{ }^{\circ} \mathrm{C}$ selama 2 jam dan proses hidrotermal dilakukan pada temperatur $180{ }^{\circ} \mathrm{C}$ selama 6 jam. Sampel yang dihasilkan berbentuk serbuk diuji menggunakan XRD. Grafik XRD dianalisis dengan software Match! 3 untuk menentukan jenis zeolit yang terbentuk. Proses sintesis pada temperatur hidrotermal $180{ }^{\circ} \mathrm{C}$ menghasilkan zeolit dengan pori berukuran relatif kecil dengan diameter sekitar $5 \dot{A}$ sampai $7 \dot{A}$. Produk utama yang dihasilkan dari Na100-K0 berupa Sodalit dan Zeolit ZK-14, dari Na75-K25 berupa Hidrosodalit dan Kalsilit, dari Na50:K50 berupa Kalsilit, sedangkan dari Na25-K75 dan Na0-K100 berupa Megakalsilit. Sampel dengan nilai kristalinitas terbesar adalah Na100-K0 dengan nilai kristalinitas mencapai $100 \%$. Secara umum dapat disimpulkan lewat proses sintesis bahwa kation $\mathrm{K}$ akan menghambat pertumbuhan kristal zeolit dengan kation Na karena sifat kation K yang dominan terhadap kation Na.

Kata kunci: abu dasar, hidrotermal, peleburan alkali,zeolit
\end{abstract}

\section{ABSTRACT}

Synthesis of zeolites from coal bottom ash with fusion step followed by hydrothermal method using $\mathrm{NaOH}$ and $\mathrm{KOH}$ as cation source has been done. The ratio of cation mole and the mass of bottom ash is 0.36 mole: $12 \mathrm{~g}$. Mole ratio of $\mathrm{NaOH}$ and $\mathrm{KOH}$ for each samples are 100\%:0\% (Na100-KO), 75\%:25\% (Na75K25), 50\%:50\% (Na50-K50), 25\%:75\% (Na25:K75) and 0\%:100\% (Na0-K100). Fusion step was conducted at temperature $550^{\circ} \mathrm{C}$ for 2 hours and hydrothermal treatment was conducted at $180^{\circ} \mathrm{C}$ for 6 hours. Powder products of synthesis were characterized by XRD. XRD graph is analyzed using Match!3 software to determine the phases of synthetic zeolites. Synthesis at temperature $180^{\circ} \mathrm{C}$ formed zeolites with relatively small pore sizes with diameter about $5 \dot{A}$ to $7 \dot{A}$. Major products of Na100-KO are Sodalite and Zeolite ZK-14, from Na75-K25 are Hydrosodalite and Kalsilite, from Na50-K50 is Kalsilite, whereas from Na25-K75 and Na0-K100 are Megakalsilites. Sample with highest crystallinity is Na100-KO with crystallinity reach $100 \%$. Overall, K cations are observed distrupting crystal growths of zeolites with $\mathrm{Na}$ cations, because of dominant properties of $K$ cations to Na cations.

Keywords:bottom ash, fusion step, hydrothermal,zeolite

\section{PENDAHULUAN}

Zeolit adalah material berpori mikro hingga nano yang tersusun dari kristal-kristal aluminosilikat. Zeolit memiliki struktur dasar tetrahedral $\mathrm{TO}_{4}$,dimana $\mathrm{T}$ merupakan atom $\mathrm{Si}$ atau $\mathrm{Al}$, dan atom $\mathrm{O}$ sebagai atom yang diikat bersama antar tetangga kristal. Zeolit memiliki rumus empiris $\mathrm{M}_{\mathrm{x} / \mathrm{n}}\left[\left(\mathrm{AlO}_{2}\right)_{\mathrm{x}}\left(\mathrm{SiO}_{2}\right)_{\mathrm{y}}\right] \cdot \mathrm{zH}_{2} \mathrm{O}$, dimana $\mathrm{M}$ adalah kation dengan valensi $\mathrm{n}$ (Payra dan Dutta, 2003).

Jenis zeolit ditentukan oleh kerangka dari zeolit. Kerangka dari zeolit adalah struktur yang terbentuk antar tetrahedral $\mathrm{TO}_{4}$. Penamaan struktur zeolit ditunjukkan dengan 3 huruf kapital (Baerlocher dkk., 2007). Dari struktur yang sama, selanjutnya bisa juga memiliki zeolit dengan jenis dan kandungan unsur yang berbeda, sebagai contoh linde type A dan ZK-4 memiliki struktur LTA, kemudian NaX dan NaY(faujasit) memiliki struktur FAU.

Aplikasi dari zeolitsangat dipengaruhi oleh rongga dan sifat kation yang mudah disubtitusi pada zeolit. Secara garis besar ada 3 aplikasi dari zeolit, yaitu sebagai absorben, katalis, dan penukar ion (Jury dkk., 2014).Aplikasi ini mencakup berbagai bidang; mulai dari sebagai bahan dasar deterjen (Association of Detergent Zeolite Producers, 2000), medis 
(Pavelic dan Hadjiza, 2003), pertanian dan peternakan (Mumpton, 1985), penanganan limbah (Trinh dkk., 2014; von Eckstaedt dkk., 2015) sampai elektronika (Izci dan Izci, 2007; Chen dkk., 2015).

Zeolit dapat disintesis di laboratorium dari berbagai jenis senyawa lain yang memiliki kandungan aluminosilikat. Salah satu yang bisa digunakan adalah abu dasar batubara.Abu dasar yang akan digunakan pada penelitian ini didapat dari PLTU Ombilin. Penyusun utama dari abu dasar yang berasal dari PLTU Ombilin ini adalah $\mathrm{SiO}_{2}$ dan $\mathrm{Al}_{2} \mathrm{O}_{3}$ dengan persentase massa masing-masingnya sebesar 57\% dan 36\% (Oktaviani, 2015).

Salah satu metode sintesis abu dasar menjadi zeolit adalah metode peleburan alkali hidrotermal. Banyak faktor yang mempengaruhi jenis dan sifat zeolit yang dihasilkan dari proses sintesis dengan metode peleburan alkali hidrotermal, mulai dari komposisi bahan dasar yang digunakan, perbandingan $\mathrm{Si} / \mathrm{Al}$ dari bahan dasar, alkalinitas, sampai temperatur dan waktu pada proses sintesis yang dilakukan. Faktor lain yang mempengaruhi adalah jenis dan komposisi dari medium basa sekaligus sumber kation yang digunakan. Perbedaan hasil sintesis bisa didapat selain karena kation berbeda akan menghasilkan zeolit berbeda, juga bisa disebabkan salah satu kation yang mempengaruhi kation yang lain. Sifat saling mempengaruhi ini bisa disebabkan oleh perbedaan templating ability dari masing-masing kation (Xu dkk, 2007).

Oktaviani (2015)telah melakukan sintesis zeolit dengan metode peleburan alkali hidrotermal menggunakan $\mathrm{NaOH}$ sebagai sumber kation. Pada sampel dengan nilai temperatur hidrotermal $180{ }^{\circ} \mathrm{C}$, Oktaviani (2015) mendapatkanzeolitberupa sodalit (SOD). Sintesis zeolit dengan menggunakan $\mathrm{KOH}$ sebagai sumber kation dan medium basa juga sudah pernah dilakukan, seperti yang dilakukan oleh Fansuri dkk. (2009). Fansuri dkk. (2009) melakukan metode hidrotermal langsung tetapi melalui 2 tahap hidrotermal, dimana diberikan variasi temperatur pada tahap hidrotermal pertama dan tahap hidrotermal kedua dilakukan pada temperatur $100^{\circ} \mathrm{C}$.Fansuridkk. (2009) mendapatkan hasil berupa phillipsit (PHI) untuk sampel dengan nilai temperatur hidrotermal pertama yang mendekati $180{ }^{\circ} \mathrm{C}$.

Sintesis zeolit pada penelitian ini dilakukan dengan metode peleburan alkali hidrotermalmengikuti metode penelitian dari Oktaviani (2015) dengan variasi komposisi perbandingan medium basa $\mathrm{NaOH}$ terhadap $\mathrm{KOH}$ sebagai berikut; $100 \%: 0 \%, 75 \%: 25 \%, 50 \%$ $: 50 \%, 25 \%: 75 \%$ dan 0\%: 100\%.Penelitian bertujuan untuk menentukan pengaruh dari sumber kation sekaligus medium basa berupa $\mathrm{NaOH}$ dan $\mathrm{KOH}$ terhadap jenis dari zeolit sintetis yang dihasilkan lewat proses peleburan alkali hidrotermal. Pada penelitian akan diamati dan ditentukan hal-hal seperti; jenis zeolit berbeda yang bisa dihasilkan dari sumber kation yang berbeda dan hubungan antara 2 buah kation itu sendiri (bagaimana $\mathrm{Na}$ dan $\mathrm{K}$ akan saling mempengaruhi pada proses pembentukan zeolit). Selain itu, penelitian ini diharapkan akan membuka ruang untuk pemanfaatan limbah batubara, seperti dalam hal ini untuk pembuatan zeolit.

\section{METODE}

\subsection{Sintesis Zeolit}

Abu dasar dari PLTU Ombilin yang akan digunakan terlebih dahulu dikeringkan, dihaluskan dan di ayak dengan ayakan 200 mesh untuk mendapatkan ukuran yang lebih seragam. Untuk lebih memastikan tidak terdapatnya air, abu dasar dipanaskan didalam oven pada suhu $100{ }^{\circ} \mathrm{C}$.

Pada langkah selanjutnya, disiapkan 5 buah sampel dimana masing-masingnya $12 \mathrm{~g}$ abu dasar dicampur dan diaduk hingga merata dengan 0,36 mol campuran $\mathrm{NaOH}$ dan $\mathrm{KOH}$. Perbandingan mol antara $\mathrm{NaOH}$ dan $\mathrm{KOH}$ yang digunakan sebesar 100\%:0\% (sampel Na100K0), 75\% : 25\% (sampel Na75-K25), 50\% : 50\% (sampel Na50-K50), 25\% : 75\% (sampel $\mathrm{Na} 25-\mathrm{K} 75$ ) dan 0\%: 100\% (sampel Na0-K100). Masing-masing sampel kemudian dilebur dengan cara dipanaskan didalam furnace pada suhu $550{ }^{\circ} \mathrm{C}$ selama dua jam. Setelah dipanaskan, sampel dikeluarkan dari furnace, didinginkan dan kemudian dihaluskan.

Selanjutnya masing-masing $10 \mathrm{~g}$ sampel dilarutkan dengan $50 \mathrm{ml}$ air laut, untuk kemudian diaduk menggunakan magnetic stirrer selama 30 menit. Setelah itu, masing-masing 
sampel dimasukkan ke dalam reaktor hidrotermal (teflon autoclave) yang kemudian dimasukkan kedalam oven dengan temperatur $180{ }^{\circ} \mathrm{C}$ selama 6 jam. Setelah dipanaskan, sampel dikeluarkan dari reaktor hidrotermal, dikeringkan, dan selanjutnya digiling menggunakan mortar sehingga diperoleh zeolit dalam bentuk serbuk.

\subsection{Karakterisasi Zeolit}

Untuk menentukan struktur kristal zeolit dan jenis zeolit, serbuk zeolit dikarakterisasi menggunakan XRD (X-Ray Difraction) dan selanjutnya dianalisis menggunakan program Match! 3 dan Diamond 4.

\section{HASIL DAN DISKUSI}

Dari proses sintesis yang dilakukan, didapat 5 buah sampel berupa serbuk dengan warna hitam keabu-abuan seperti terlihat pada Gambar 1.Analisis grafik XRD sampel menggunakansoftware Match! 3.Analisis tahap pertama dilakukan dengan memilih fase-fase yang mungkin terbentuk, yaitu berupa senyawa tektosilikat, dan didapat daftar kandidat (candidate list) dengan nilai FoM (Figure of Merit, berupa nilai kemiripan grafik sampel dengan database) tertinggi seperti ditunjukkan pada Tabel 1.

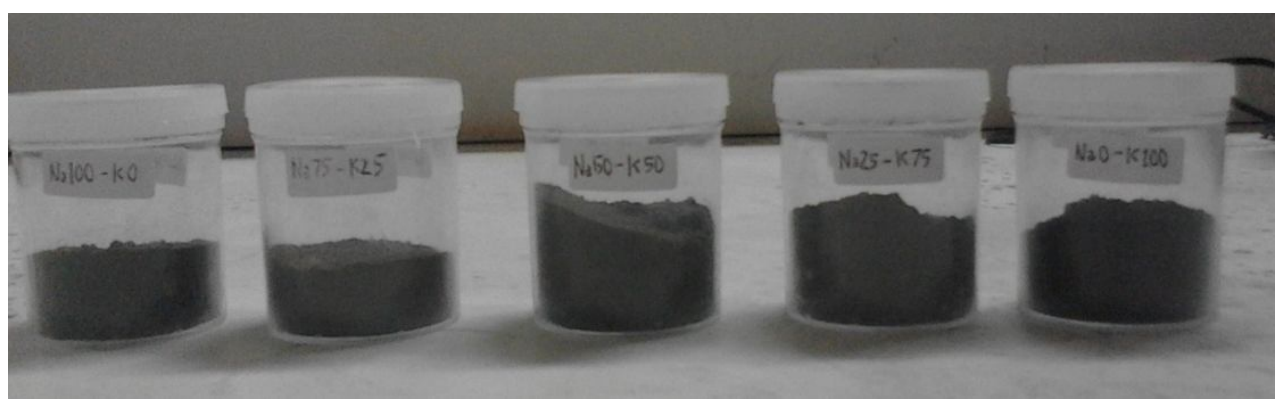

Gambar 1 Serbuk sampel hasil sintesis abu dasar dengan variasi $\mathrm{NaOH}: \mathrm{KOH}$

Tabel 1 Daftar kandidat fase dari grafik XRD masing-masing sampel dengan nilai FoM

\begin{tabular}{|c|c|c|c|c|}
\hline \multicolumn{5}{|c|}{ Nama sampel / Kandidat fase (FoM) } \\
\hline Na100-K0 & Na75-K25 & Na50-K50 & Na25-K75 & Na0-K100 \\
\hline ZK-14 & Kalsilite & Kalsilite & Quartz & Megakalsilite \\
$(0,7912)$ & $(0,7864)$ & $(0,7904)$ & $(0,7786)$ & $(0,7867)$ \\
\hline Sodalite & Quartz & Quartz & Megakalsilite & Kalsilite \\
$(0,7400)$ & $(0,7702)$ & $(0,7627)$ & $(0,7716)$ & $(0,7599)$ \\
\hline Hydrosodalite & Montesommaite & Montesommaite & Montesommaite & Quartz \\
$(0,6619)$ & $(0,7441)$ & $(0,7227)$ & $(0,6944)$ & $(0,7422)$ \\
\hline Analcime & Hydrosodalite $(0$ & Megakalsilite & Sanidine & Sanidine \\
$(0,6588)$ & $, 7337)$ & $(0,7083)$ & $(0,6661)$ & $(0,6375)$ \\
\hline Clinoptilolite & Megakalsilite & Carnegieite high & Leucite & Silimanite \\
$(0,6519)$ & $(0,7143)$ & $(0,6939)$ & $(0,6632)$ & $(0,6214)$ \\
\hline
\end{tabular}

Sebagaimana terlihat pada Tabel 1, dari daftar kandidat fase pada setiap sampel hasil sintesis, tidak ada nilai FoM yang mencapai 1. Nilai FoM sama dengan 1 hanya akan terjadi apabila grafik dari sampel sama persis dengan grafik fase pada database. Dari kelima sampel yang ada,nilai maksimum dari FoM adalah 0,7912 pada Na100-K0 dan selanjutnya 0,7904 untuk Na50-K50. Dari nilai FoM ini dapat dilihat bahwa semua sampel tidak menghasilkan satu jenis kristal yang murni yang sama dengan fase pada database yang digunakan sebagai acuan.

Perbedaan nilai FoM juga akan ditunjukkan oleh adanya perbedaan puncak-puncak grafik sampel jika dibandingkan dengan grafik database. Sebagai contoh seperti ditampilkan pada Tabel 2 dan Gambar 2(a), dimana puncak pada posisi $2 \theta=28,24^{\circ} ; 40,37^{\circ}$ dan $69,81^{\circ}$ dari fase Zeolit ZK-14 (yang merupakan fase dengan nilai FoM tertinggi dengan sampel Na100-K0) tidak ditemukan pada grafik XRD sampel Na100-K0. Kemudian pada database Zeolit ZK-14 ada puncak pada $2 \theta=17,19^{\circ}$, sementara pada sampel ditemukan puncak pada $2 \theta=$ $16,90^{\circ}$.Hilang atau bergesernya puncak pada databaseyang dibandingkan dengan grafik sampel 128 
dapat terjadi karena adanya atom yang terdapat pada fase di database tapi tidak ada pada sampel, atau sebaliknya, ataupun juga bisa dikarenakan perubahan sudut dari kerangka kristal sampel dibandingkan database.

Tabel 2 Perbandingan puncak antara fase Zeolit ZK-14 dan sampel Na100-K0

\begin{tabular}{|c|c|}
\hline $2 \theta$ Zeolit ZK-14 $\left(^{0}\right)$ & $2 \theta$ Sampel Na100-K0 $\left(^{\circ}\right)$ \\
\hline 14,01 & 13,96 \\
\hline 14,05 & 14,12 \\
\hline 17,19 & 16,90 \\
\hline 24,40 & 24,40 \\
\hline 28,24 & - \\
\hline 31,66 & 31,60 \\
\hline 34,77 & 34,79 \\
\hline 40,37 & - \\
\hline 43,05 & 42,99 \\
\hline 52,33 & 52,26 \\
\hline 62,51 & 62,43 \\
\hline 69,81 & - \\
\hline 78,67 & 78,61 \\
\hline
\end{tabular}

Analisis lebih lanjut dari daftar kandidat dilakukan untuk menentukan fase mana yang dipilih dari daftar kandidat tersebut. Pertimbangan yang digunakan adalah posisi puncak-puncak yang berimpit dan jumlah unsur yang diketahui terdapat pada bahan.Hasil analisis ditampilkan seperti pada Gambar 2 dan daftar fase beserta persentase pada Tabel 3.

Pada sampel Na100-K0, diperoleh fase Sodalit dan Zeolit ZK-14. Sampel Na100-K0 inimerupakan sampel yang sama dengan salah satu variasi yang pernah dilakukan oleh Oktaviani (2015), dan didapat hasil yang relatif sama yaitu berupa Sodalit (SOD). Sodalit, Zeolit ZK-14 dan Hidrosodalit memiliki struktur yang sama, yaitu SOD. Zeolit dengan struktur SOD merupakan zeolit dengan ukuran pori kecil, dimana pori terbesarnya terbentuk dari hanya 6 atom T dengan diameter sekitar $6 \dot{A}$. Sodalit, Zeolit ZK-14 dan Hidrosodalit memiliki nilai framework density (FD) yang relatif sama, yaitu sebesar 17 atom T per 1000 Ȧ.Kalsilit dan Megakalsilit serta Carnegiete high memiliki nilai FD sebesar 20 atom T per 1000 Á. Leusit (ANA) walaupun memiliki pori yang terbentuk dari 8 atom $\mathrm{T}$, tetapi sepasang atom berseberangan pada sistem cincin berjarak sebesar 5,96 $\dot{\mathrm{A}}$, dan memiliki nilai FD sebesar 22 atom $\mathrm{T}$ per $1000 \dot{\mathrm{A}}$.

Nilai FD menunjukkan kerapatan struktur, nilai FD yang lebih besar berarti struktur yanglebih rapat. Struktur yang lebih rapat akan berhubungan dengan pori yang lebih kecil. Zeolit dan produk lain yang didapat dari penelitian ini memiliki nilai FD yang relatif besar. Hasil ini diperkirakan berkaitan dengan temperatur yang digunakan pada proses hidrotermal. Temperatur $180{ }^{\circ} \mathrm{C}$ adalah temperatur yang relatif tinggi untuk proses hidrotermal, sehingga mengakibatkan produk yang dihasilkan memiliki pori yang relatif kecil (Xu dkk, 2007). Kemungkinan, jika menggunakan temperatur yang lebih rendah akan diperoleh zeolit yang berbeda dengan ukuran pori yang lebih besar, sebagaimana yang ada juga dilakukan oleh Oktaviani (2015) dengan variasi temperatur hidrotermal pada $80{ }^{\circ} \mathrm{C}$ dan $100{ }^{\circ} \mathrm{C}$.

Secara umum dapat diamati bagaimana keberadaan kation $\mathrm{K}$ menghambat pertumbuhan kristal zeolit dengan kation Na. Sebagai contoh pada sampel Na100-K0, hampir semua komponen abu dasar berubah menjadi zeolit dengan kation Na, baik Sodalit maupun Zeolit ZK14; tetapi pada sampel Na75-K25 hanya terbentuk sekitar $25 \%$ zeolit dengan kation Na (Hidrosodalit) dari keseluruhan produk. Walaupun penurunan jumlah kation Na dari Na100-K0 dibandingkan Na75-K25 hanya berkurang dari 0,36 mol ke 0,27 mol, tetapi keberadaan 0,09 mol kation K cukup untuk menyebabkan perubahan ini.

Hal ini menunjukkan perbedaan templating ability dari kedua jenis kation ( $\mathrm{Na}$ dan $\mathrm{K}$ ). Perbedaan templating ability salah satunya dipengaruhi oleh ukuran dari kation (Xu,2007). Ion 
$\mathrm{K}(2,27 \dot{\mathrm{A}})$ yang berukuran lebih besar dibandingkan ion $\mathrm{Na}(1,8 \dot{\mathrm{A}})$, terlihat bersifat menghambat terhadap pertumbuhan kristal zeolit dengan ion $\mathrm{Na}$, terutama pada kristal zeolit dengan ukuran pori yang relatif kecil.

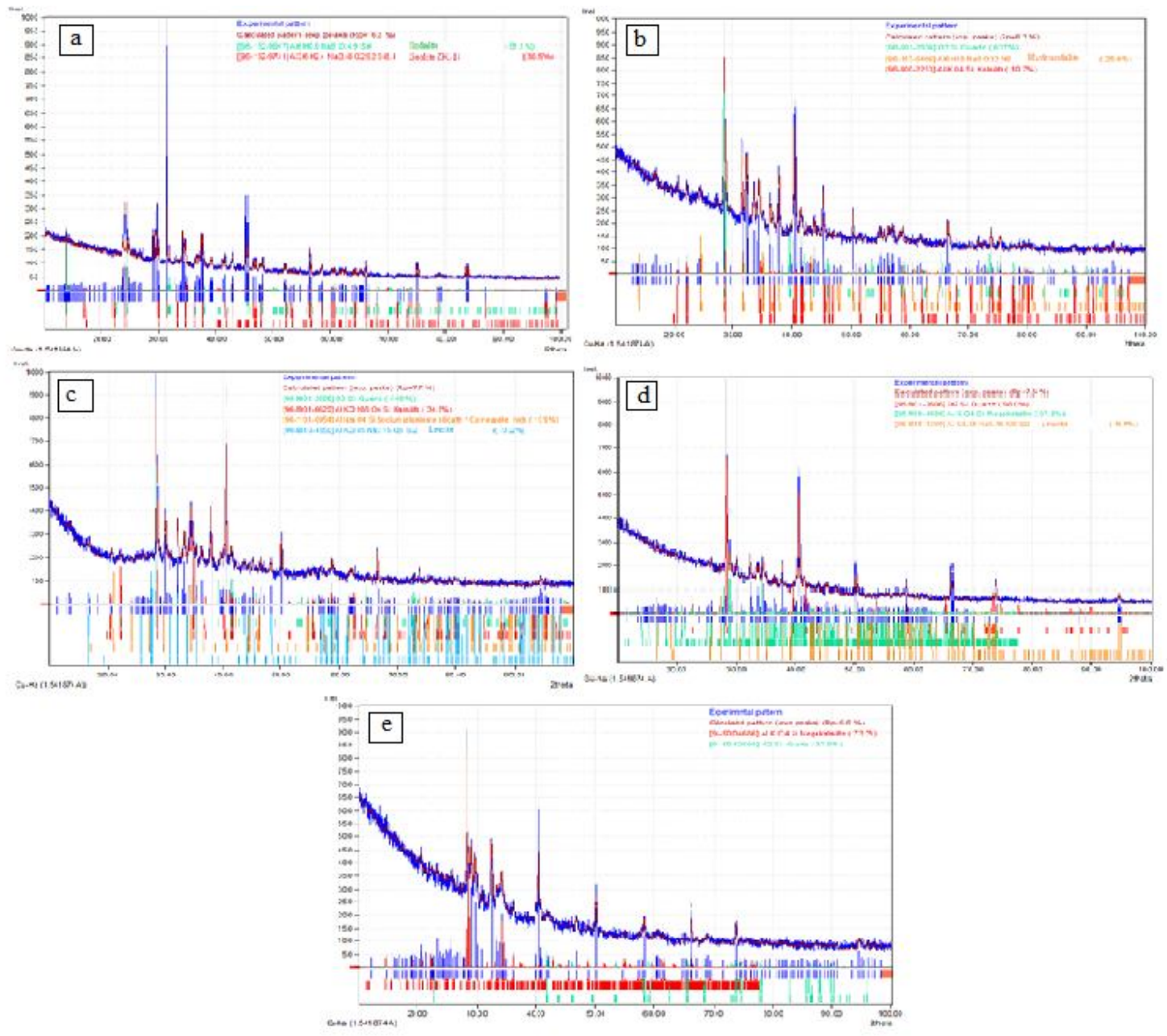

Gambar 2 Hasil analisis grafik XRD pada sampel (a)Na100-K0, (b)Na75-K25, (c)Na50-

K50, (d)Na25-K75 dan (e)Na0-K100

Tabel 3 Daftar fase dan persentase hasil sintesis masing-masing sampel.

\begin{tabular}{|l|l|l|l|l|}
\hline \multicolumn{5}{|c|}{ Nama sampel / Nama fase (Persentase) } \\
\hline Na100-K0 & Na75-K25 & \multicolumn{1}{|c|}{ Na50-K50 } & Na25-K75 & \multicolumn{1}{|c|}{ Na0-K100 } \\
\hline- Sodalit & - Kuarsa & - Kuarsa & - Kuarsa & -Megakalsilit \\
$(61,1 \%)$ & $(63,7 \%)$ & $(44,9 \%)$ & $(56,0 \%)$ & $(73 \%)$ \\
- ZK-14 & - Hidrosodalit & - Kalsilit & - -Megakalsilit & - -Kuarsa \\
$(38,9 \%)$ & $(25,6 \%)$ & $(34 \%)$ & $(37,6 \%)$ & $(27,0 \%)$ \\
& - Kalsilit & - - arnegiete high & -Leusit & \\
& $(10,7 \%)$ & $(10,9 \%)$ & $(6,4 \%)$ & \\
& & - Leusit & & \\
& & $(10,2 \%)$ & & \\
& & & & \\
\end{tabular}

Untuk kristalinitas produk dari masing-masing sampel sendiri bisa dilihat dari bahan dasar (kuarsa dan mullit) yang tersisa pada produk. Kristalinitas yang tinggi akan berarti banyak berkurangnya atau bahkan habisnya jumlah kuarsa dan mullit karena kuarsa dan mullit berubah menjadi zeolit atau produk lain; dan sebaliknya jika kuarsa dan mullit yang tersisa relatif banyak maka akan berarti nilai kristalinitas yang rendah. Seperti tertera pada Tabel 3, kristalinitas tertinggi adalah pada Na100-K0 (kuarsa dan mullit tersisa 0\%) dan terendah adalah pada Na75-K25 (kuarsa tersisa 63,7\%).Tingkat kristalinitas salah satunya ditentukan oleh waktu 
kristalisasi. Pada sampel yang tingkat kristalinitasnya masih rendah ada kemungkinan disebabkan karena waktu hidrotermal yang digunakan masih kurang. Kristalinitas yang lebih tinggi akan membutuhkan waktu hidrotermal yang lebih lama.

\section{KESIMPULAN}

Dari sampel dengan sumber kation $\mathrm{NaOH}$ (Na100-K0) didapat Sodalit (SOD) dan Zeolit ZK-14 (SOD). Dari sampel dengan kandungan sumber kation 75\% NaOH dan 25\% KOH (Na75-K25) didapat Hidrosodalit (SOD) dan Kalsilit. Dari sampel dengan kandungan sumber kation 50\% NaOH dan 50\% KOH (Na50-K50) didapat Kalsilit, Carnegiete high dan Leusit (ANA). Dari sampel dengan kandungan sumber kation 25\% NaOH dan 75\% KOH (Na25-K75) didapat Megakalsilit dan Leusit (ANA). Dari sampel dengan sumber kation KOH (Na0-K100) didapat Megakalsilit. Dari penelitian yang telah dilakukan, diamati bahwa adanya kation K akan menghambat pertumbuhan dari kristal zeolit dengan kation Na. Produk yang dihasilkan dengan proses peleburan alkali hidrotermal pada suhu hidrotermal $180{ }^{\circ} \mathrm{C}$ menghasilkan produk dengan pori yang relatif kecil (berkisar $6 \dot{A}$ ).Kristalinitas tertinggi diantara 5 sampel adalah pada Na100-K0 yang mencapai $100 \%$.

\section{DAFTAR PUSTAKA}

Association of Detergent Zeolite Producers, Zeolites for Detergents as Nature Intended, (Cefic, Brussels, 2000).

Baerlocher, C., McCusker, L.B. dan Olson, D.H., Atlas of Zeolite Framework Types: Sixth Revised Edition, Appl. Phys. Letters 85, 2503-2504 (2004).

Chen, Y., Zhang, Y., Li, D., Gao, F., Feng, C., Wen, S. dan Ruan, S., Sensors and Actuators, Vol.212 (2015), hal. 242-247.

Fansuri, H., Prasetyoko, D. dan Muasyaroh, D.,Effect of Initial hydrothermal Temperatures to Zeolite Products In the Synthesis of Zeolites from Coal Fly Ash, CR-Room Proceeding, (CHEMECA, Perth, 2009).

Izci E. dan Izci A., Turk J Chem, Vol.31 (2007), hal. 523-530.

Jury, F.A., Polaert, I., Estel, L. dan Pierella, L.B., Microporous and Mesoporous Materials, Vol.198 (2014), hal. 22-28.

Mumpton, F.A.,Innovative Biological Technologies for Lesser Developed Countries, (Department of the Earth SciencesState University College,New York, 2015).

Oktaviani, Y.,"Pengaruh Temperatur Hidrotermal terhadap Konduktivitas Listrik Zeolit Sintesis dari Abu Dasar Batubara dengan Metode Alkali Hidrotermal", Skripsi S1, Universitas Andalas, Padang, 2015.

Pavelic, K. dan Hadzija, M., Handbook of Zeolite Science and Technology, (Marcell Dekker, Inc, 2003), hal. 1141-1172.

Payra, P. dan Dutta, P.K.,Handbook of Zeolite Science and Technology, (Marcell Dekker, Inc, 2003), hal. 1-19.

Trinh Q.H., Lee, S.B. dan Mok, Y.S., Journal of Hazardous Materials, Vol. 285(2014), hal.525-534.

Von Eckstaedt, S.V., Charles, W., Ho, G. dan Cord-Ruwisch, R.,. Chemosphere,Vol.144 (2015), hal.257-263.

$\mathrm{Xu}$, R., Pang, W., Yu, J., Huo, Q. dan Chen, J.,Chemistry of Zeolites and Related Porous Materials: Synthesis and Structure, (John Wiley \& Sons, Singapore, 2007). 